\title{
¿Policentrismo o ampliación de la centralidad histórica en el Área Metropolitana del Gran Santiago? Evidencia novedosa proveniente de la encuesta Casen 2009
}

\begin{abstract}
Jorge Rodríguez V. Centro Latinoamericano y Caribeño de Demografía (Celade) División de Población de la Comisión Económica para América Latina y el Caribe (Cepal) de las Naciones Unidas, Santiago, Chile.
\end{abstract}

RESUMEN | Se usan los módulos de "movilidad cotidiana para trabajar" del censo de población de 2002 y de la Encuesta de Caracterización Socioeconómica Nacional (Casen) de 2009, de Chile, para verificar las hipótesis del avance del policentrismo y de la "difusión del empleo" en el Área Metropolitana del Gran Santiago (AMGS, Chile), planteadas por estudios recientes. Ambas hipótesis se ajustan tanto a las predicciones de las teorías del cambio metropolitano predominantes, como a la experiencia de numerosas ciudades de los países desarrollados y de América Latina. Sin embargo, en ellas se tiende a desconocer el efecto que la segregación residencial socioeconómica a gran escala del AMGS tiene sobre la localización del empleo. La evidencia sistematizada en este trabajo sugiere un proceso mixto en el AMGS: nuevas subcentralidades aparecen, pero no contrapesan aún el predominio económico de la centralidad histórica ampliada.

PALABRAS CLAVE $\mid$ movilidad cotidiana, economía urbana, segregación.

\begin{abstract}
Questions on commuting from the 2002 Population Census and the 2009 Casen (National Socioeconomic Characterization) survey of Chile are used for assessing two hypotheses raised in some recent articles about the Metropolitan Area of Greater Santiago (MAGS): i) the advancement of polycentrism, and ii) territorial diffusion of employment across the MAGS. Both hypotheses are based on mainstream theories of metropolitan change, and have been supported by evidence from several cities, mostly in developed countries. However, these hypotheses do not take the effects of Santiago's high levels of residential segregation into account. According to results obtained in this study, the MAGS is experiencing a mixed process: new centralities indeed are arising but they do not overshadow yet the concentration of employment in the wider historic centrality.
\end{abstract}

KEY WORDS | commuting, urban economy, segregation. 


\section{Introducción}

Por primera vez, la encuesta de Caracterización Socioeconómica Nacional de 2009 (Casen 2009; www.mideplan.cl/casen) incluyó preguntas sobre movilidad diaria para trabajar o estudiar (Figura 1). Se trata de dos consultas. Una (t10 de la figura 1) es muy similar a la incluida en el censo de 2002 ( 16 de la Figura 2), aunque se diferencia en términos de su localización dentro de la boleta y la población consultada. La otra (t11 en la figura 1), en cambio, no se incluyó en el censo de 2002.

FIgURA 1 | Preguntas sobre movilidad diaria de la encuesta Casen 2009

\begin{tabular}{|l|}
\hline \multicolumn{1}{|c|}{15 años y más } \\
\hline t10. ¿En qué comuna trabaja (o estudia si no trabaja)? \\
1. En esta comuna \\
2. En otra comuna ¿en qué otra comuna? \\
3. No trabaja ni estudia $\longrightarrow$ pase a pregunta t12 \\
Sólo a quienes responden 1 ó 2 en la \\
pregunta t10 y edad 15 años o más \\
t11. ¿Qué modo de transporte usa la mayor \\
parte de las veces, en dia de semana, para \\
ir al trabajo (o al lugar de estudio si no \\
trabaja)? \\
1.Solamente a pie, en bicicleta u otra forma de \\
transporte no motorizada (como a caballo, en \\
bote, etc.) \\
2. Auto, moto u otro transporte motorizado privado \\
(como taxi o radio-taxi) \\
3. Bus, taxi colectivo u otro transporte motorizado \\
público (como metro, micro, tren, lancha, barcaza, \\
avión etc.) \\
4. Combina transporte motorizado privado (2) y \\
transporte motorizado público (3) \\
5. Otro (como transporte escolar, transporte \\
institucional, etc.) \\
6. No se desplaza
\end{tabular}

Varios factores realzan esta información. El primero es que ofrece una oportunidad original para examinar tendencias en materia de movilidad cotidiana ${ }^{1}$ mediante la comparación del censo de 2002 con la Casen 2009, lo que, en todo caso, deberá ser efectuado con cautela, por consideraciones que se exponen en el marco

1 En este trabajo se usará la expresión 'movilidad cotidiana' para referirse exclusivamente al desplazamiento que las personas hacen a su trabajo principal, según su propia declaración. Puede ser un desplazamiento de frecuencia diaria o con otra frecuencia (sea regular, por ejemplo semanal en el caso del trabajo mediante turnos en la minería y otras faenas de ese tipo, o irregular), lo que no es investigado en el censo ni en la encuesta. En inglés, la palabra apropiada para este desplazamiento sería commuting y en portugués, pendularidade. 
metodológico. El segundo es que aporta evidencia novedosa y fresca sobre temas que actualmente se debaten con intensidad, en el caso de Santiago y en el de otras metrópolis del mundo, tanto en términos conceptuales como operativos y de política. Entre estos temas están: i) la dispersión territorial del empleo metropolitano en el marco del tránsito de ciudades monocéntricas a ciudades policéntricas; ii) las desigualdades sociales en materia de movilidad cotidiana; iii) el "encapsulamiento" de las clases altas y la segregación de los pobres; y iv) la consolidación de la movilidad cotidiana dentro de las metrópolis - en particular en el caso del Área Metropolitana del Gran Santiago (AMGS) luego de la implementación del nuevo sistema de transporte colectivo (Transantiago) - , como asunto prioritario de política pública y de gobernabilidad, eficiencia y calidad de vida (De Mattos, 2010; Delaunay, 2010; Dureau \& Gouëset, 2010; Rodríguez, 2008a y 2007; De Mattos \& Hidalgo, 2007; Galetovic \& Jordán, 2006; Graham \& Marvin, 2001; Ingram, 1998).

Considerando que se trata de una oportunidad original y teniendo en cuenta el escaso uso que los cientistas sociales chilenos le han dado al módulo de movilidad cotidiana del censo - no obstante los valiosos e interesantes resultados que entregó-, este estudio se propone explorar ambas fuentes para arrojar luz, con una perspectiva sociodemográfica, sobre dos hipótesis que se retroalimentan, que han sido levantadas recientemente en la literatura especializada (De Mattos, 2010; Galetovic \& Jordan, 2006; Escolano \& Ortiz, 2005; Janoska, 2002), y que ameritan mayor discusión conceptual y un trabajo empírico específico. Las hipótesis dicen relación con: i) el paso desde un AMGS monocéntrica a un AMGS policéntrica; y ii) la difusión territorial de los empleos por el AMGS.

FIGURA 2 | Pregunta sobre movilidad diaria del censo 2002

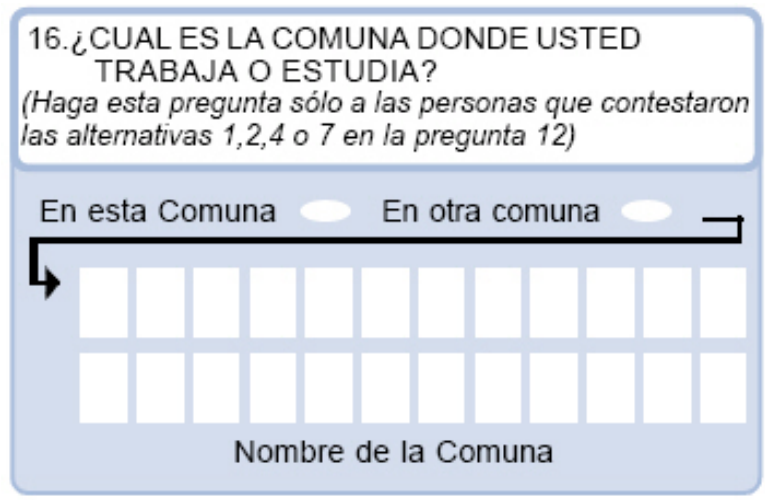




\section{Discusión conceptual}

El pronóstico de ciudades multicéntricas y de desconcentración territorial del empleo metropolitano proviene de, al menos, dos vertientes conceptuales diferentes.

Por una parte, está el marco conceptual que denominaremos de la "metrópoli posindustrial", recientemente sintetizado con una dosis de sensibilidad y perspectiva latinoamericana por De Mattos (2010). Este enfoque plantea que, producto de un conjunto de procesos concomitantes - entre ellos, interconexión a distancias crecientes, revolución tecnológica, nueva modalidad de producción mediante ensamblaje inteligente, creciente terciarización, aumento de los ingresos-, todas las ciudades, incluyendo las de América Latina, transitan hacia una condición que se denomina, genéricamente, "lo urbano" generalizado. Entre los rasgos distintivos de esta metamorfosis están: i) la constitución de ciudades interconectadas, regionesciudades y ciudades difusas, lo que contrasta con la ciudad compacta y de densidad decreciente con el alejamiento del centro, típicos del urbano industrial; ii) la creciente terciarización del empleo, que tiene implicaciones territoriales directas por la mayor posibilidad de desvincular empleo y residencia en el sector terciario; iii) la emergencia de externalidades productivas en red que facilitan la dispersión y favorecen el policentrismo, en contra del monocentrismo de la ciudad compacta de la fase industrial. La siguiente cita es ilustrativa de este planteamiento:

De tal forma, también el comportamiento dominante en las decisiones y en las acciones de localización adoptadas por empresas de diversa naturaleza y dimensión mostró una fuerte preferencia por sitios cada vez más alejados de la parte central de las aglomeraciones metropolitanas. Frente a esta tendencia a la periurbanización, en muchos casos, diferentes instancias gubernamentales desplegaron esfuerzos orientados a frenar o controlar la metropolización expandida emergente; sin embargo, la fuerza incontenible de la dinámica autoorganizativa sustentada en el comportamiento locacional de un número cada día mayor de familias y de empresas, hizo que por lo general estos esfuerzos no pudieran lograr mucho más que alterar parcialmente dicha tendencia, pero en ningún caso revertirla. (De Mattos, 2010, p. 95)

Por otra parte está la economía urbana neoclásica y un conjunto de hechos estilizados, anticipados o consistentes al menos con este corpus teórico, en materia de localización de empresas, suburbanización de la población, relación positiva entre ingresos y demanda de espacio residencial y capacidad de pago de transporte privado (Escolano \& Ortiz, 2005; Wheaton, 2002; Ingram, 1998; Polese, 1998). En el caso del AMGS, Galetovic y Jordan (2006a y 2006b) usan este marco conceptual (y también el de metrópoli posindustrial) para apoyar el pronóstico del reemplazo del centro tradicional del AMGS por una variedad de centros (entre ellos, el histórico y su prolongación hacia el oriente a través de la misma). En el caso de Santiago, estos autores plantean de manera directa lo siguiente: 
Si Santiago sigue al resto de las grandes áreas metropolitanas de países desarrollados, su centro se especializará en aquellos servicios que exigen contacto cara a cara y comunicación eficaz — principalmente financieros, jurídicos y consultorías demandadas por las grandes empresas-. Pero "el centro" se extenderá más allá de las ocho manzanas alrededor de la Plaza de Armas por todo el corredor que parte en la Alameda, continúa por la avenida Providencia y termina en Apoquindo en el barrio El Bosque y aun más allá. El resto de los servicios debiera esparcirse por toda la ciudad, pues el comercio seguirá a los hogares. Esto ocurrirá porque los mayores ingresos permiten sostener volúmenes de ventas más altos - la escala dará para más que una sola gran área comercial en el centro-. Algo así ya se aprecia con los malls, que han proliferado por todo Santiago y seguirán construyéndose cerca de las autopistas urbanas. (Galetovic \& Jordan, 2006, p. 131)

Ambos enfoques teóricos tienen sólidos fundamentos, tanto conceptuales como empíricos. Pero su sustento principal proviene de la experiencia de los países de mayor desarrollo económico y social, lo que introduce dudas respecto de su idoneidad para el análisis y la predicción de escenarios futuros en el caso de las ciudades de países de menor desarrollo, entre ellas las de América Latina. A continuación se explica por qué las especificidades de las ciudades de América Latina, en particular del AMGS, podrían contrarrestar las tendencias hacia el policentrismo.

Los marcos teóricos hegemónicos, en particular los dos comentados, establecen una retroalimentación entre la dispersión de la población y la dispersión del empleo. Respecto de lo primero no hay dudas, toda vez que están relativamente bien identificados los mecanismos económicos y sociales que provocan el paulatino traspaso del área central a actividades productivas, en particular comerciales y de servicios, y el consiguiente reforzamiento del papel residencial de la periferia (Angel, Parent, Civco \& Blei , 2011; Ingram, 1998; Polese, 1998). Por lo demás, la evidencia histórica muestra efectivamente una atenuación del ritmo de expansión demográfica de las áreas centrales — cuya población tiende a decrecer, incluso, en muchas de ellas - y, en marcado contraste, un acelerado crecimiento de la periferia, procesos evidentemente vinculados, ya que el desplazamiento del centro a la periferia es un factor clave para ello. Esta dispersión de la población provoca necesariamente algún grado de dispersión del empleo, en particular para la satisfacción de las necesidades cotidianas (comercio detallista, atención médica primaria, educación preescolar y básica, etcétera). Sin embargo, no es obvio que aquello sea el factor causal para la dispersión metropolitana de otras actividades productivas, como las industriales y las de servicios masivos. En efecto, estas actividades pueden desarrollarse en instalaciones concentradas en ciertos puntos de la ciudad. En el caso del comercio y los servicios, su ubicación puede mantener un sesgo central significativo, justamente porque están bien conectados y su ubicación promedio no es particularmente lejana, sobre todo para los grupos con mayor poder adquisitivo.

Entonces, el mecanismo clave ya no depende de la localización de la población, sino de la localización de las empresas. En general, las teorías dominantes identifican varios mecanismos económicos y políticos por los cuales las firmas tienden a 
salir del centro y diseminarse por el resto de la ciudad (Ingram, 1998; Polese, 1998). Esto es claro en el caso de los grandes establecimientos fabriles, que se trasladan masivamente sea a la periferia metropolitana (parques industriales) o a otras partes del país o del mundo, o bien tienden a desaparecer. Pero en el caso de las empresas de servicios - las más dinámicas y generadoras de empleo bajo la globalización-, la racionalidad de tal traslado no es tan evidente. El argumento más esgrimido por los enfoques dominantes es la reducción de costos. Precisamente esto se lograría mediante el traslado a sitios periféricos, donde el suelo es más barato, normalmente hay menos gastos por congestión e inseguridad y los impuestos locales suelen ser menores. Y ciertamente, estos traslados se verían facilitados por las nuevas conectividades y, con ello, la pérdida de relevancia del factor distancia.

Sin embargo, más que reducir costos, los empresarios y ejecutivos se interesan por tener ganancias, siendo la reducción de costos uno de los mecanismos para lograrlo. Si la reducción de costos trae aparejada una merma superior de ingresos, evidentemente no tendría sentido tal traslado. Si bien este balance entre costos e ingresos pareciera estar claro en el caso de las actividades primarias y secundarias - altamente intensivas en uso del espacio y por ello más proclives a considerar el costo del suelo como factor clave en sus decisiones de localización-, y en varias de las comerciales, no lo es tanto en el caso de algunas terciarias, justamente aquellas dinámicas, altamente absorbentes de empleos de todo tipo que adquieren preeminencia en la ciudad posindustrial. Se trata de actividades de oficina, que suelen ser poco intensivas en espacio, entre otras cosas porque pueden desarrollarse sin dificultades en edificación de altura; además, suelen requerir de acceso fácil y disponibilidad de servicios asociados aledaños (restaurantes para la alimentación de los oficinistas, tiendas especializadas en los productos requeridos por el giro comercial, hoteles para eventuales clientes o consultores foráneos, bancos y dependencias públicas para realizar trámites financieros y administrativos presenciales). Más aún, la conectividad y la visibilidad global introducen criterios de distinción, que llevan a las empresas a valorar simbólicamente la localización en las zonas de alta figuración, típicamente caras, en el centro o en barrios comerciales y financieros selectos. Por último, quienes toman las decisiones de localización de las empresas son sus dueños, accionistas y gerentes, los que suelen estar interesados en tener tiempos de viaje al trabajo cortos y en mantenerse cerca de potenciales ejecutivos y clientes de alto perfil, lo que retroalimenta la instalación o permanencia en la zona de altos ingresos. Por todo lo anterior, los establecimientos y oficinas de los sectores dinámicos de la economía pueden concentrarse fuertemente en las centralidades históricas o empujar su expansión, sin decaer frente a la emergencia de nuevas subcentralidades.

Adicionalmente, una multitud de servicios personales, comunales y sociales - como servicios domésticos, de cuidado, de vigilancia; manejo de jardines, atención en restaurantes, instrucción en gimnasios; aseo y ornato de hogares, negocios y calles; empleo en establecimientos comerciales y sucursales bancarias; atención médica, de enfermería y apoyo auxiliar en hospitales, clínicas y consultas particulares - son requeridos en una tasa mucho mayor que el promedio por parte del 
segmento más acomodado de la sociedad. Por ello, si los hogares más pudientes se dispersan por la ciudad, un conjunto de servicios y empleos los seguirán, como ha ocurrido con los suburbios en muchas ciudades de los Estados Unidos. Pero si, por el contrario, estos hogares se concentran en una zona de la ciudad, esta ejercerá un fuerte atractivo para la localización de firmas y viajes de trabajo diario.

En el caso del AMGS, que es el analizado en el presente trabajo, se plantea que la dispersión de los puestos de trabajo se dará conjuntamente con una proyección hacia el oriente de la zona histórica de concentración del empleo. Esta última ha sido la comuna central de Santiago, pero desde hace décadas el centro comercial principal se ha articulado con las comunas de Providencia y Las Condes, en torno al eje vial estructurante Alameda-Providencia-Las Condes. En los últimos años, la expansión ha alcanzado más subcentros de las comunas de Providencia y Las Condes y ha sumado nuevos ámbitos de dinamismo comercial en otras comunas del Cono Oriente, a saber, Vitacura, Lo Barnechea, La Reina y Nuñoa. Esto último es reforzado por el nivel de demanda efectiva y el simbolismo de esa zona, ya que, como se indicó y como se aprecia claramente en la Figura 3, el Cono Oriente es el área de la ciudad donde se localiza la población de altos ingresos y donde está la infraestructura de oficinas privadas, servicios de apoyo, dependencias públicas y reparticiones municipales más poderosa y dinámica de la ciudad y del país (Orellana, 2009; Rodríguez, 2008b).

Cabe subrayar que, a primera vista, esta hipótesis ya ha sido levantada en estudios con los que el presente trabajo más bien polemiza, como el de Galetovic y Jordan (2006), con el que hay al menos dos diferencias importantes. Para estos autores, la dispersión del empleo parece ser de una magnitud tal que la centralidad principal queda opacada por las centralidades emergentes. Asimismo, sostienen que la dispersión es de una transversalidad geográfica tal que las centralidades emergentes brotarían en todas o casi todas las comunas. En cambio, aquí se plantea la persistencia del atractivo de la centralidad principal — en línea con lo sugerido por Tokman (2006) y Escolano y Ortiz (2005) con datos previos-, aun bajo las condiciones adversas que suponen la dispersión demográfica y la difusión de los denominados "artefactos de la globalización" (grandes centros comerciales, supermercados e incluso complejos de oficinas).

Lo anterior obliga a matizar la noción de dispersión del empleo, pues en el AMGS el predominio del centro acotado del pasado (Central Business District) no sería sucedido por una red de nodos relativamente equivalentes distribuidos por todas las zonas de la ciudad. Más bien, se expresaría en términos de una centralidad histórica dominante en el núcleo centro-oriente (comunas de Santiago, Providencia y Las Condes, en particular) y subcentralidades emergentes en comunas periféricas, en particular aquellas donde hay espacio, demanda potencial y conectividad suficiente para la localización de los "artefactos de la globalización”, que son fuente masiva de empleos. Aquí es donde la distinción entre retención, atracción y atractivo se hace crucial, ya que la aparición de centros comerciales de tamaño mediano y grande podría eventualmente reducir ciertos viajes de compras (asunto 
no estudiado en este trabajo) y generar empleo para residentes, aumentando la retención (que sí será medida en este trabajo). Pero generar empleos que logren atraer masivamente trabajadores requiere de una difusión generalizada de las actividades productivas, lo que choca con la concentración de los principales servicios en la centralidad histórica dominante, como se demostrará en este documento. Por eso, la hipótesis del presente texto atañe al atractivo de las comunas, más que a su capacidad de retención de trabajadores residentes en ellas.

FIGURA 3 | AMGS: Comunas componentes, según nivel de ingreso

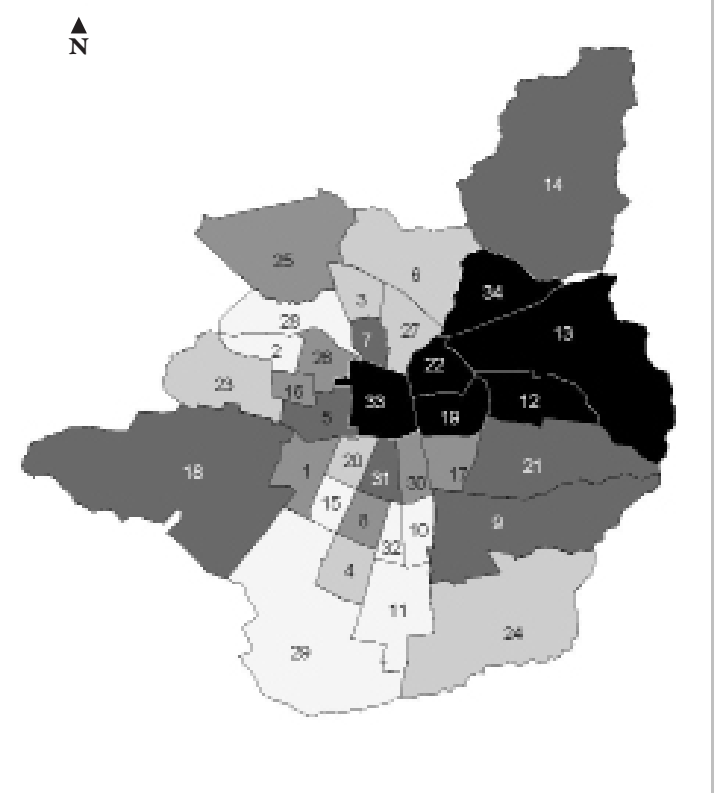

COMUNAS QUE CONFORMAN EL GRAN SANTIAGO:

1 Cerrillos 18 Maipú

2 Cerro Navia 19 Ňñño

3 Conchalí 20 Pedro Aguirre Cerd

4 El Bosque 21 Peñalolén

5 Estación Central 22 Providencia

6 Huechuraba 23 Pudahuel

7 Independencia 24 Puente Alto

8 La Cisterna 25 Quilicura

9 La Florida 26 Quinta Normal

10 La Granja 27 Recoleta

11 La Pintana 28 Renca

12 La Reina 29 San Bernardo

13 Las Condes 30 San Joaquín

14 Lo Barnechea 31 San Miguel

15 Lo Espejo 32 San Ramón

16 Lo Prado 33 Santiago

17 Macul 34 Vitacura

PROMEDIO DECIL DE INGRESO

4.12 a 5.23

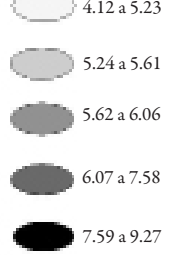

FUENTE ELABORACIÓN PROPIA, VALORES OBTENIDOS MEDIANTE PROCESAMIENTOS ESPECIALES DE LA BASE DE MICRODATOS DE LA CASEN 2009.

nota 1 En algunas comunas (Pudahuel, San Bernardo y Lo Barnechea) Se excluyen distritos rurales. NOTA 2 El INDICADOR USADO ES EL PROMEDIO COMUNAL DEL DECIL DE INGRESOS REgIONAL. MientRAS MÁS CERCA DE 10, MÁS RICA LA COMUNA.

\section{Marco metodológico y operacionalización de las hipótesis}

\section{Fuente, procesamiento y comparabilidad de las consultas}

Se usaron los microdatos del censo de 2002 y de la encuesta Casen 2009, que se procesaron con Redatam (censo), y con SPSS-17 y Redatam (Casen). La comparabilidad entre ambas fuentes no es total, por varias razones. La más obvia es que 
la encuesta tiene un error muestral asociado y sus estimaciones de punto, como las que se usarán regularmente en este trabajo, tienen un intervalo de confianza ${ }^{2}$, el que debe ser considerado en el cotejo. Luego se diferencian en términos de ubicación de la pregunta sobre movilidad cotidiana dentro de la boleta, ya que en el censo se enmarca en el módulo de actividad económica de la población, mientras que en la Casen 2009, en el módulo de temas emergentes. Finalmente, la Casen hace más preguntas que el censo para captar actividad económica, lo que debiera afectar la cantidad de los ocupados que encuentra, así como su perfil. Los efectos de estas diferencias no son obvios, pero la mayor profundidad de la Casen para capturar ocupados - en particular ocupados por cuenta propia o familiares no remuneradospermite suponer que implicará una elevación de los índices de retención laboral, porque tales trabajos tienen más probabilidad de realizarse en la casa de residencia o en lugares aledaños a ella. ${ }^{3}$

\section{Variables dependientes, definiciones territoriales y variables de segmentación socioterritorial}

La principal variable que se usará en este estudio será la "condición de movilidad” y será dicotómica: "no móvil”, que son las personas que trabajan en la misma comuna en que residen; ${ }^{4}$ y "móvil", que son las personas que trabajan en una comuna diferente de la que residen. ${ }^{5}$ El análisis se centra en los residentes en el AMGS, ${ }^{6}$ aunque algunos cálculos incluyen afuerinos.

La centralidad histórica tradicional (comuna de Santiago) casi no será objeto de examen específico en este trabajo, ya que, en línea con lo expuesto en el marco teórico, se postula su reemplazo por una centralidad ampliada que incluye las comunas de Santiago, Providencia y Las Condes. Para evaluar la eventual extensión de esta centralidad hacia el resto del Cono Oriente, se examinará también una centralidad extendida, que incluye las tres comunas anteriores, más Lo Barnechea, Vitacura, Nunñoa y La Reina; es decir, el denominado Cono Oriente (Rodríguez, 2008) más la comuna de Santiago.

\section{Instrumentos e indicadores}

El principal instrumento de análisis será la matriz de origen y destino que, en su expresión original, será de 37 por 37. En efecto, se incluyen las 34 comunas del AMG, más: i) el grupo de comunas de la Región Metropolitana que no forman parte del

2 Estos intervalos de confianza fueron calculados por Marco Galván y Fernando Medina (estadísticos de la División de Estadística y Proyecciones Económicas de la CEPAL) considerando el efecto diseño comunal.

3 Como lo revelan los mismos datos de la Casen 2009, mientras la probabilidad de ser móvil intrametropolitano era del $70 \%$ en el caso de los asalariados, apenas llegaba al 27,6\% en el caso de los trabajadores por cuenta propia.

4 Por tanto, estos trabajadores no son forzosamente estáticos; de hecho, la gran mayoría "viaja" a su trabajo y algunos pueden recorrer distancias no menores o gastar tiempo importante de viaje en ciertas comunas grandes o congestionadas, pero no deben salir de su comuna para trabajar. Esa es su especificidad.

5 Se excluyeron del análisis personas que trabajan en otro país (en torno a 1.400 casos).

6 Treinta y dos comunas de la provincia de Santiago, más Puente Alto y San Bernardo. 
AMGS; ii) el grupo de comunas de otras regiones del país; y iii) los marginales (totales). ${ }^{7}$ Por cierto, los patrones de movilidad entre los dos grupos de comunas fuera del AMGS no serán objeto de estudio en este trabajo, ya que solo se considerarán sus intercambios cotidianos para trabajar con las comunas del AMGS.

\section{Indicadores}

Se usan tres indicadores, todos ellos calculados a partir de la matriz de origen y destino. Se medirán:

1) El índice de retención de cada comuna —o agrupación de comunas, en particular la centralidad histórica, sea en su configuración ampliada o su configuración extendida-, mediante el porcentaje que todos los ocupados residentes en ella y que trabajan en ella, representan en el total de ocupados residentes en ella. Utilizando la nomenclatura específica, el algoritmo de cálculo del índice de retención, que es una proporción y, por ende, tiene un recorrido definido y conocido, es:

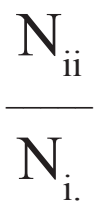

siendo $\mathrm{N}_{\mathrm{ii}}$ la población ocupada que reside en la comuna i y trabaja en la misma comuna i, y $\mathrm{N}_{\mathrm{i} \text {. }}$ la población ocupada residente en la comuna i.

2) El índice de atracción de cada comuna —o agrupación de comunas, en particular la centralidad histórica, sea en su configuración ampliada o su configuración extendida-, mediante la relación entre personas que llegan a trabajar allí y el total de ocupados que reside allí. Utilizando la nomenclatura específica, el algoritmo de cálculo del índice de atracción, que es una relación y, por ende, tiene un recorrido indefinido y dependiente de la cuantía de los flujos involucrados, es:

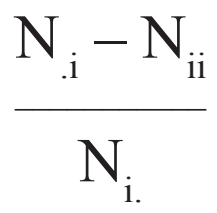

siendo $\mathrm{N}_{\text {.i }}$ la población ocupada que trabaja en la comuna i, $\mathrm{N}_{\mathrm{ii}}$ la población ocupada que reside en la comuna i y trabaja en la misma comuna i, y $\mathrm{N}_{\mathrm{i}}$ la población ocupada residente en la comuna i.

7 Para efecto de las fórmulas de los indicadores, cabe definir la nomenclatura específica de esta matriz. Esta corresponde a la típica de una matriz de origen y destino. Nij es la población que se desplaza de la comuna $i$ a la comuna $j$, en este caso la que reside en la comuna $i$ y trabaja en la comuna $j$. Nii es la población que trabaja en la misma comuna en que reside. N.i es el total de población que trabaja en la comuna $i$. Ni. es el total de población que reside en la comuna $i$. 
3) El índice de atractivo de la comuna - o agrupación de comunas, en particular la centralidad histórica, sea en su configuración ampliada o su configuración extendida-, mediante la relación entre la diferencia de personas que llegan a trabajar allí y personas que salen de allí para trabajar (numerador) y la población ocupada residente (denominador). Utilizando la nomenclatura específica, el algoritmo de cálculo del índice de atracción, que es una relación y, por ende, tiene un recorrido indefinido y dependiente de la cuantía de los flujos involucrados, es:

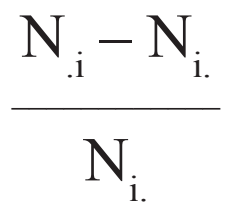

siendo $\mathrm{N}_{\mathrm{i}}$ la población ocupada que trabaja en la comuna $\mathrm{i}, \mathrm{y} \mathrm{N}_{\mathrm{i} \text {. }}$ la población ocupada residente en la comuna i.

\section{Procedimientos y análisis estadísticos}

Los procedimientos corresponden a los cálculos de los indicadores y sus comparaciones, tanto entre fuentes (considerando los intervalos de confianza en el caso de la Casen 2009) como entre comunas y/o áreas de la ciudad. Además, estos indicadores serán objeto de análisis estadísticos bivariados y multivariados para hallar asociaciones, tanto entre ellos como con el nivel socioeconómico de las comunas, en directa relación con las hipótesis que se exponen operacionalmente a continuación.

\section{Operacionalización de hipótesis}

a) Los niveles de retención de las comunas aumentan, en particular en aquellas que han experimentado mutaciones metropolitanas posindustriales.

b) La retención de la centralidad histórica ampliada y extendida también aumenta.

c) La proporción del empleo del AMGS que se localiza en la centralidad histórica ampliada y extendida se mantiene o se reduce ligeramente.

d) Por la pertinaz concentración del empleo en la centralidad histórica ampliada y extendida, la cantidad relativa de trabajadores que se desplazan hacia allá se mantiene o aumenta.

e) Tanto la retención como el atractivo están relacionados positivamente con el nivel socioeconómico de la comuna, pero la relación es más marcada en el caso del atractivo. 


\section{Resultados}

\section{La retención según comunas}

Respecto de la primera hipótesis de este trabajo, a saber, un aumento generalizado de los niveles de retención de todas las comunas —incluso en las de alta concentración de empleo y alto nivel de retención en 2002 - la evidencia la valida plenamente. En el Cuadro 1 se aprecia que prácticamente todas las comunas registran un alza de sus índices de retención. El cálculo de los intervalos de confianza asociados a cada estimación de punto de 2009 indica que, en la gran mayoría de los casos, el cambio es estadísticamente significativo.

En varios casos se trata de alzas significativas, que superan los 15 puntos porcentuales, destacando el de Huechuraba. Este es emblemático, ya que en esta comuna se han verificado los dos procesos más significativos de mutación metropolitana posindustrial, tal como se expuso en el marco teórico, a saber: i) traslado de familias de altos ingresos provenientes del Cono Oriente a condominios cerrados o urbanizaciones de construcción reciente de alto nivel; ii) diseminación de artefactos de la globalización, incluyendo un núcleo de edificios de oficinas y servicios de proyección nacional ("Ciudad Empresarial”). Los resultados sugieren una multiplicación de las opciones de empleo en las comunas, al menos para sus residentes, lo que apoya la hipótesis de subcentralidades emergentes dispersas por la metrópoli. No importa si estas centralidades emergentes se deben a la apertura de conexiones con la centralidad histórica ampliada o extendida, ${ }^{8}$ ya que incluso considerando la aparición de tal nexo, el planteamiento central se mantiene, cual es la aparición de nuevos polos de empleo dentro de la ciudad.

El resto de las comunas con aumentos sobresalientes del índice de retención corresponde a realidades diversas, para las cuales no hay explicaciones evidentes. De hecho, entre ellas están varias del denominado "pericentro expulsor" (Rodríguez, 2008b) - como La Granja, Pedro Aguirre Cerda, Cerro Navia, Conchalí y San Joaquín-, que no han destacado por recibir artefactos de la modernización y/o constituir nuevas centralidades, lo que introduce dudas sobre esta relación entre centralidad emergente y capacidad de retención. Hay explicaciones alternativas. Entre ellas están las dos siguientes, cuya exploración quedará para futuras investigaciones: i) el desarrollo de actividades productivas próximas a las nuevas líneas de Metro que, por ejemplo, llegaron por vez primera a comunas como Conchalí y La Granja (aunque también podría argumentarse que el efecto principal de esta nueva conectividad es facilitar los desplazamientos para trabajar fuera de la comuna, debilitando, así, la retención); y ii) los efectos adversos del sistema de transporte colectivo Transantiago en sus primeras etapas, que pudieron haber afectado los desplazamientos para trabajar fuera de esas comunas, incentivado el trabajo dentro de la comuna, menos dependiente de ese tipo de transporte.

Por otra parte, también abona las hipótesis de avance del policentrismo y debilitamiento del centro principal el hecho de que las dos comunas en las que baja el in-

8 Precisamente lo que aconteció, por ejemplo, en el caso de Huechuraba, vía apertura de la avenida Américo Vespucio Norte a través del cerro San Cristóbal en el sector de La Pirámide y mediante la construcción del túnel que atraviesa el cerro San Cristóbal y une directamente Huechuraba con Providencia. 
dicador de retención sean Las Condes y Lo Barnechea, integrantes de la centralidad histórica extendida (también ampliada en el caso de Las Condes). Estos datos relativizarían, en principio, los planteamientos esgrimidos en este trabajo sobre el reforzamiento de la centralidad histórica mediante su ampliación hacia la zona oriente.

Pero no cabe sacar conclusiones apresuradas de este primer cuadro, porque el análisis por comuna pierde uno de los atributos clave que se han relevado en este trabajo, cual es que en el AMGS coexisten dos procesos que se enfrentan, uno de "desconcentración concentrada” del empleo, que se expresa en la expansión de la centralidad histórica hacia el oriente (sea en su modalidad ampliada o extendida); y otro de desconcentración efectiva del empleo, que se expresa en la aparición de nuevas subcentralidades. Por lo mismo, el análisis relevante del primer proceso debe considerar la retención y, en particular, la atracción del conjunto de comunas que conforman esta centralidad histórica ampliada y extendida, lo que se hace a continuación.

\section{Retención del centro comercial ampliado y del centro comercial extendido y su relación con la retención comunal}

Como se explicó en el marco conceptual, la extensión del centro comercial tradicional puede implicar un contrapeso firme a la multiplicación de subcentralidades en el resto de la ciudad, por lo que el análisis de la retención debe efectuarse para dicha entidad. Al hacerlo se advierte un aumento importante (y estadísticamente significativo con un nivel de confianza de 95\%), ya que en el caso de la centralidad histórica ampliada (Santiago, Las Condes, Providencia) pasa del 71,5\% al 75,9\%; y en el caso del centro comercial extendido, del 76,7\% al 81,6\%. Vale decir, su ya sobresalientemente alto nivel de retención aumentó entre 2002 y 2009 (Cuadro 2). Desde un punto de vista sociourbano, la conclusión es clara: para la gran mayoría de los ocupados residentes de la centralidad hegemónica, no es necesario salir para trabajar; de hecho, cuando se considera la centralidad histórica extendida, solo 1 de cada 5 ocupados residentes debe hacerlo.

Dada la coincidencia entre esta centralidad y el ámbito de localización del grupo pudiente, estas cifras parecen un aval contundente de los planteamientos efectuados por la prensa en los últimos años sobre la denominada ciudad "cota mil". Con todo, tal conclusión debe ser matizada, porque los resultados están influidos por la pertinaz gravitación de la comuna de Santiago (técnicamente fuera del Cono Oriente o el "barrio alto") en materia de empleo. Pero incluso teniendo en cuenta este último factor, el hecho concreto que es necesario destacar es que 80,7\% (cifra no mostrada en el cuadro) de los ocupados residentes del "barrio alto" (solo seis comunas, porque excluye la de Santiago) trabaja en la centralidad histórica extendida, por lo cual su conocimiento y contacto con el resto de la ciudad — la ciudad de la mayoría, la ciudad corriente, la ciudad de nivel socioeconómico medio y pobreson, probablemente, limitados.

9 En el AMGS, los hogares de altos ingresos están fuertemente concentrados en el denominado Cono Oriente - donde reside el 15,8\% del total de hogares y el 61,4\% de los hogares del decil superior de ingresos (jerarquía regional), según la Casen 2009, cálculos propios-, que ocupa la parte alta de la ciudad. La "ciudad cota mil" es una expresión retórica, porque en los hechos hay poca población y mancha urbana por sobre ese nivel, pero la localización del estrato socioeconómico elevado en las partes altas de la ciudad queda claramente reflejada en la tradicional expresión "barrio alto", que genéricamente se usa para referirse al Cono Oriente. 
CUADRO 1 | AMGS (34 comunas): Evolución del porcentaje de retención según comuna

\begin{tabular}{|c|c|c|c|}
\hline COMUNA & 2002 & 2009 & $\begin{array}{l}\text { CAMBIO } \\
2002-2009\end{array}$ \\
\hline SANTIAGO & 51,8 & 62,8 & 10,9 \\
\hline CERRILLOS & 28,2 & 40,0 & 11,8 \\
\hline CERRO NAVIA & 20,9 & 37,8 & 16,9 \\
\hline CONCHALÍ & 22,4 & 37,4 & 15,0 \\
\hline EL BOSQUE & 21,9 & 31,3 & 9,4 \\
\hline ESTACIÓN CENTRAL & 28,0 & 36,5 & 8,4 \\
\hline HUECHURABA & 25,3 & 49,9 & 24,6 \\
\hline INDEPENDENCIA & 29,4 & 36,2 & 6,8 \\
\hline LA CISTERNA & 26,6 & 40,0 & 13,4 \\
\hline LA FLORIDA & 21,8 & 33,5 & 11,7 \\
\hline LA GRANJA & 20,4 & 41,1 & 20,7 \\
\hline LA PINTANA & 18,7 & 32,0 & 13,3 \\
\hline LA REINA & 26,6 & 26,0 & $-0,6$ \\
\hline LAS CONDES & 41,0 & 39,0 & $-2,0$ \\
\hline LO BARNECHEA & 48,2 & 52,6 & 4,4 \\
\hline LO ESPEJO & 22,3 & 32,3 & 10,0 \\
\hline LO PRADO & 15,7 & 25,5 & 9,7 \\
\hline MACUL & 22,3 & 37,2 & 14,9 \\
\hline MAIPÚ & 25,8 & 34,9 & 9,1 \\
\hline ÑUÑOA & 22,0 & 28,0 & 6,0 \\
\hline PEDRO AGUIRRE CERDA & 23,0 & 37,8 & 14,7 \\
\hline PEÑALOLÉN & 22,3 & 37,8 & 15,5 \\
\hline PROVIDENCIA & 39,7 & 46,6 & 6,9 \\
\hline PUDAHUEL & 22,1 & 30,7 & 8,5 \\
\hline QUILICURA & 29,3 & 41,2 & 11,9 \\
\hline QUINTA NORMAL & 32,3 & 37,9 & 5,6 \\
\hline RECOLETA & 31,7 & 39,9 & 8,2 \\
\hline RENCA & 25,8 & 32,3 & 6,6 \\
\hline SAN JOAQUÍN & 25,2 & 43,5 & 18,3 \\
\hline SAN MIGUEL & 27,5 & 28,7 & 1,2 \\
\hline SAN RAMÓN & 20,1 & 29,9 & 9,9 \\
\hline VITACURA & 36,9 & 51,0 & 14,1 \\
\hline PUENTE ALTO & 25,5 & 36,4 & 10,9 \\
\hline SAN BERNARDO & 41,0 & 52,7 & 11,7 \\
\hline
\end{tabular}

fuente Procesamientos especiales microdatos censo 2002 y Casen 2009. 
CUADRO 2 | AMGS (34 comunas): Cantidades globales y porcentajes de ocupados en el centro comercial ampliado y el centro comercial extendido, 2002 y 2009.

\begin{tabular}{l|c|c}
\hline CIFRAS E INDICADORES & 2002 & 2009 \\
\hline $\begin{array}{l}\text { Cantidad de ocupados residentes en el centro comercial ampliado que } \\
\text { trabajan en el centro comercial ampliado }\end{array}$ & 173.598 & 224.358 \\
Cantidad de ocupados residentes en el centro comercial ampliado & 242.639 & 295.687 \\
$\begin{array}{l}\text { Porcentaje de retención del centro comercial ampliado } \\
\text { Cantidad de ocupados residentes en el centro comercial extendido que }\end{array}$ & 71,5 & 75,9 \\
trabajan en el centro comercial extendido & 309.620 & 399.063 \\
Cantidad de ocupados residentes en el centro comercial extendido & 403.481 & 488.963 \\
\hline
\end{tabular}

fuente Procesamientos especiales microdatos censo 2002 y Casen 2009.

Cabe consignar, en todo caso, que el aumento del índice de retención de la centralidad principal, tanto en su configuración ampliada como en la extendida, es inferior, en términos relativos, al aumento registrado por el AMGS y la mayor parte de las comunas. Por ello, el índice ad hoc de ordenamiento del nivel de retención - que se calcula como el cociente entre el porcentaje de cada comuna y el porcentaje de la centralidad histórica ampliada y extendida - aumentó en casi todos los casos (Figura 4). Usando el punto de corte de 0,6 (entre 0,6 y 1 se encuentra el quintil superior de la distribución comunal de esta variable) para identificar las comunas con retención sobresaliente, se advierte una combinación de casos, pero todos previsibles teóricamente. Primero están cuatro comunas de la centralidad histórica extendida (Santiago, Providencia, Vitacura y Lo Barnechea); luego hay comunas donde se han operado mutaciones metropolitanas posindustriales (Huechuraba); finalmente hay una donde parece operar un efecto histórico, como es San Bernardo, que previamente tenía cierto grado de autarquía por su condición original de localidad independiente de Santiago. Si se usa el nivel de 0,5 aparecen otras comunas, entre ellas algunas pericentrales que conservan una estructura fabril (desde plantas grandes a talleres pequeños) importante (Cerrillos, Quinta Normal y San Joaquín) y otras periféricas que han sido usadas como destino de parques industriales (Quilicura, y el caso ya mencionado de San Bernardo); pero también existen comunas pericentrales que no parecen excepcionales en materia de empleo local (La Granja) y que, por ello, ameritan mayor estudio o al menos esperar al censo de 2012 para validar ese rasgo. 
FIGURA 4 | AMGS: Relación entre el porcentaje de retención del Centro Comercial Ampliado (CCA) y el porcentaje de retención de cada comuna, 2002 y 2009

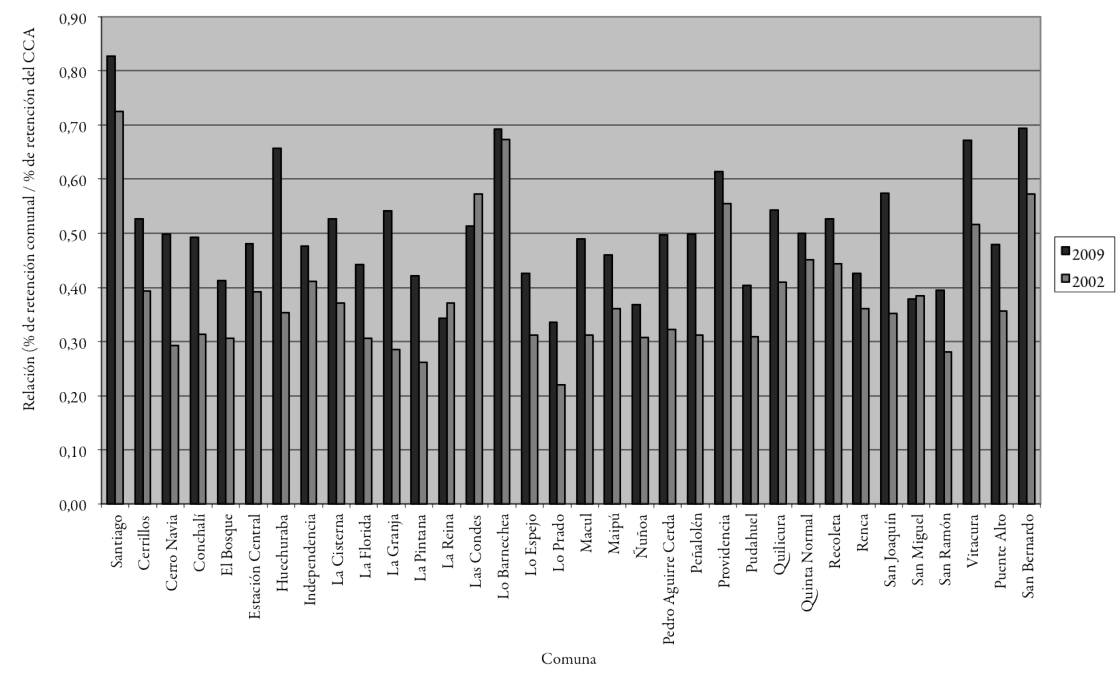

La atracción, con énfasis en las centralidades en sus diferentes configuraciones

El índice de retención no es sinónimo de nueva centralidad. En efecto, una comuna puede ser autárquica y eso claramente no la constituye en una centralidad. Esta última se define por una dotación de espacio de producción de bienes y servicios sobresaliente y, por ende, una cantidad de empleo que supera a su población y que es realizado por trabajadores que residen en otras comunas. Por ello, los niveles de atracción son más sugerentes que los de retención para identificar centralidad económica de las comunas.

Un primer antecedente empírico clave sobre la atracción está dado por la evolución de la misma en el caso de la centralidad histórica ampliada y extendida. En el Cuadro 3 se muestra una medida intuitiva del mismo, que capta el peso relativo de este espacio en el empleo global del AMGS. Y la tendencia es la predicha por el enfoque de la metrópoli posindustrial: baja la concentración del empleo en esta centralidad principal.

Ahora bien, esta tendencia debe ser matizada por varios considerandos: i) se trata de una baja más bien ligera y que, de hecho, no es estadísticamente significativa, con un nivel de confianza del 95\%; ii) la baja concomitante del peso que representan los ocupados residentes en la centralidad histórica ampliada y extendida respecto del empleo total explica la mayor parte de este descenso; iii) todavía se aprecian niveles muy altos de concentración territorial del empleo metropolitano, toda vez que el $45 \%$ del mismo se localiza en el centro comercial extendido.

Así las cosas, la gravitación de la centralidad principal en sus dos configuraciones (ampliada y extensa) pareciera mantenerse elevada, no obstante un ligero descenso entre 2002 y 2009, tendencia que debe ser monitoreada con el censo de 2012. 
CUADRo 3 | AMGS (34 comunas): Porcentaje de ocupados en el centro comercial ampliado y el centro comercial extendido, 2002 y $2009^{10}$

\begin{tabular}{|c|c|c|}
\hline CIFRAS ABSOLUTAS Y RELATIVAS & 2002 & 2009 \\
\hline $\begin{array}{l}\text { Porcentaje de ocupados en centro comercial ampliado respecto del } \\
\text { total de ocupación del AMGS }\end{array}$ & 40,3 & 37,8 \\
\hline $\begin{array}{l}\text { Porcentaje de ocupados en centro comercial extendido respecto del } \\
\text { total de ocupación del AMGS }\end{array}$ & 48,7 & 45,1 \\
\hline $\begin{array}{l}\text { Porcentaje de ocupados residentes en el centro comercial ampliado } \\
\text { respecto del empleo total del AMGS }\end{array}$ & 13,1 & 11,6 \\
\hline $\begin{array}{l}\text { Porcentaje de ocupados residentes en el centro comercial extendido } \\
\text { respecto del empleo total del AMGS }\end{array}$ & 21,7 & 19,2 \\
\hline
\end{tabular}

fuente Procesamientos especiales microdatos censo 2002 y Casen 2009.

Ahora bien, cuando se usa el índice de atracción (Figura 5), los resultados se invierten respecto del Cuadro 3, pues la tendencia es ascendente y muestra que en 2009 casi el 60\% de las personas que salía de su comuna para trabajar en el AMGS tenía por destino el centro comercial extendido, ${ }^{11}$ un ámbito donde reside menos del 20\% de los ocupados del AMGS. Nuevamente cabe prevenir sobre la significación estadística, pues se trata de un cambio ligero, que no alcanza a ser estadísticamente significativo, con un nivel de confianza del $95 \%$.

Más aún, cuando se examina el índice de atracción por comuna (Cuadro 4), se puede llegar a varias conclusiones: i) solo dos comunas exhiben niveles de atracción elevados, y son Santiago y Providencia, con índices de 3 o superiores; ii) solo unas pocas comunas superan la unidad, lo que de todas maneras revela una atracción necesariamente positiva (su magnitud final dependerá de su nivel de retención); iii) la mitad de las comunas tiene un índice de atracción bajo, de 0,5 o menos, existiendo casi una decena de casos de 0,2 o menos, lo que sugiere una escasa (relativa a la cuantía de los ocupados residentes) localización de empleos para trabajadores de otras comunas; iv) entre las comunas con bajos niveles de atracción se encuentran situaciones disímiles. Por una parte, están algunas de las periféricas de rápido crecimiento demográfico (Puente Alto y Maipú, y también La Pintana, de crecimiento menos acelerado), cuya base de empleo ha aumentado para los locales, pero no resultan muy atractivas para los trabajadores de otras comunas. Esto último probablemente se deba a las largas distancias y las dificultades de conectividad de estas comunas. ${ }^{12}$ Por otra parte, están varias de las pericentrales (Cerro Navia, Lo Prado, Pedro Aguirre Cerda, Lo Espejo, San Ramón, La Granja, El Bosque), que definitivamente no tienen establecimientos ni empleos atractivos para

10 Las cifras relativas de este cuadro no corresponden a ninguno de los tres indicadores de retención, atracción y atractivo usados en este trabajo. Se trata de porcentajes que muestran el peso relativo que tienen los puestos de trabajos localizados en las dos definiciones de centro comercial, dentro del total de la ocupación del AMGS.

11 El porcentaje superaba ligeramente el $50 \%$ si se considera solo el centro comercial ampliado. Cabe mencionar que según la Encuesta de Origen Destino de Viajes 2001 (Santiago: Pontificia Universidad Católica de Chile, Departamento de Ingeniería de Transporte/Gobierno de Chile, Ministerio de Planificación y Cooperación [Mideplan]/Secretaría Interministerial de Planificación de Transporte [Sectra], 2001), el centro ampliado atraía a casi la mitad de los viajes de trabajo en el horario punta de 7:00 a 9:00 A.M. (Tokman, 2006, p. 504). Obviamente, no cabe llegar a ninguna conclusión firme a partir de este dato, porque se trata de fuentes y variables que no son comparables.

12 Por cierto, los bajos niveles del índice de atracción en ambos casos están fuertemente influidos por la envergadura demográfica de ambas comunas, las dos más pobladas del AMGS, lo que hace numéricamente difícil que los conmutantes hacia ellas se acerquen a la cantidad de ocupados residentes en ellas. 
personas de otras comunas. Hay situaciones especiales, como la de Peñalolén, que pese a haber aumentado su retención y ser una comuna emblemática de las mutaciones metropolitanas posindustriales, no logra atraer trabajadores de otras comunas.

En definitiva, el índice de atracción ofrece un panorama más bien distinto al brindado por la retención, ya que respecto al debate que anima este trabajo (policentrismo o ampliación de la centralidad histórica), tiende a aportar evidencia más favorable a la mantención del protagonismo de la centralidad histórica, sea ampliada o extendida. En efecto, casi todas sus comunas componentes cuentan con una gran cantidad de empleos ocupados por trabajadores y trabajadoras que viven en otras comunas, revelando un pertinaz patrón de concentración de los empleos en ellas.

Solo resta examinar el índice de atractivo para tener un cuadro completo de la evolución de las centralidades comunales en materia de empleo. Justamente ese análisis se efectúa en el acápite que sigue.

FIGURA 5 | AMGS, 2002 y 2009: Evolución de la proporción de conmutantes del AMGS (totales y solo residentes en el AMGS) que tienen como destino la centralidad principal histórica en sus dos configuraciones territoriales

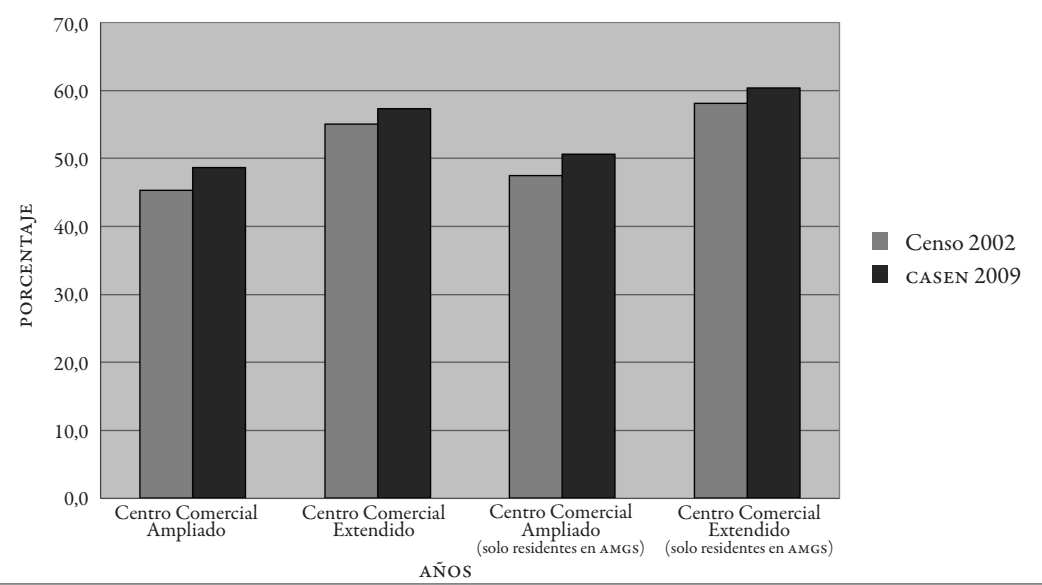

fuente Procesamientos especiales microdatos Censo 2002 y Casen 2009.

\section{El atractivo: una visión sintética}

En el Cuadro 5 se expone el índice de atractivo. Tanto en 2002 como en 2009 predominan los valores negativos: 19 comunas en 2002 y 18 en 2009. A primera vista no resultan valores muy abultados, pues la existencia de más de una docena de comunas con valor positivo sugiere la existencia de numerosas subcentralidades. Ahora bien, hay que considerar que cinco de las siete comunas que componen la centralidad histórica extendida tienen un saldo positivo en 2009 (Figura 6). Examinando, ahora, la magnitud del indicador, claramente sobresalen las comunas de la centralidad histórica ampliada y extendida, ya que las tres comunas con un indicador superior a 100 en 2009 
(que significa que el saldo de movilidad cotidiana es positivo y equivalente a los ocupados residentes) forman parte de esta centralidad (Santiago, Providencia y Vitacura). El caso de la comuna de Santiago es el más llamativo, tanto porque su atractivo está muy por encima del resto, como, sobre todo, porque aumenta entre 2002 y 2009 (y el aumento es estadísticamente significativo, con un nivel de confianza de 95\%), siendo esto último una tendencia no prevista por ningún marco teórico estándar. Así las cosas, estas cifras ratifican el atractivo que ejerce el centro comercial ampliado y extendido para los trabajadores (porque allí están concentrados los empleos) y muestran que este atractivo al menos se ha mantenido entre 2002 y 2009.

Ahora bien, las subcentralidades que identifica este indicador pueden segmentarse en tres tipos. Por un lado están las tradicionales. Estas corresponden a comunas vecinas o cercanas a la comuna central de Santiago, que históricamente han actuado como subcentros comerciales y de servicios y como ámbitos de concentración de pequeña y mediana empresa; se incluyen aquí comunas como Independencia, Estación Central, Quinta Normal, San Miguel, Recoleta, San Joaquín y Cerrillos. Por otro lado están algunas comunas emblemáticas de las mutaciones metropolitanas posindustriales, como Huechuraba. Finalmente, el atractivo de comunas como La Cisterna parece deberse a su papel como espacio de producción de bienes y servicios más vinculados a la periferia, en este caso la periferia sur del AMGS (Figura 6).

FIGURA 6 | AMGS: Comunas componentes, según índice de atractivo de trabajadores

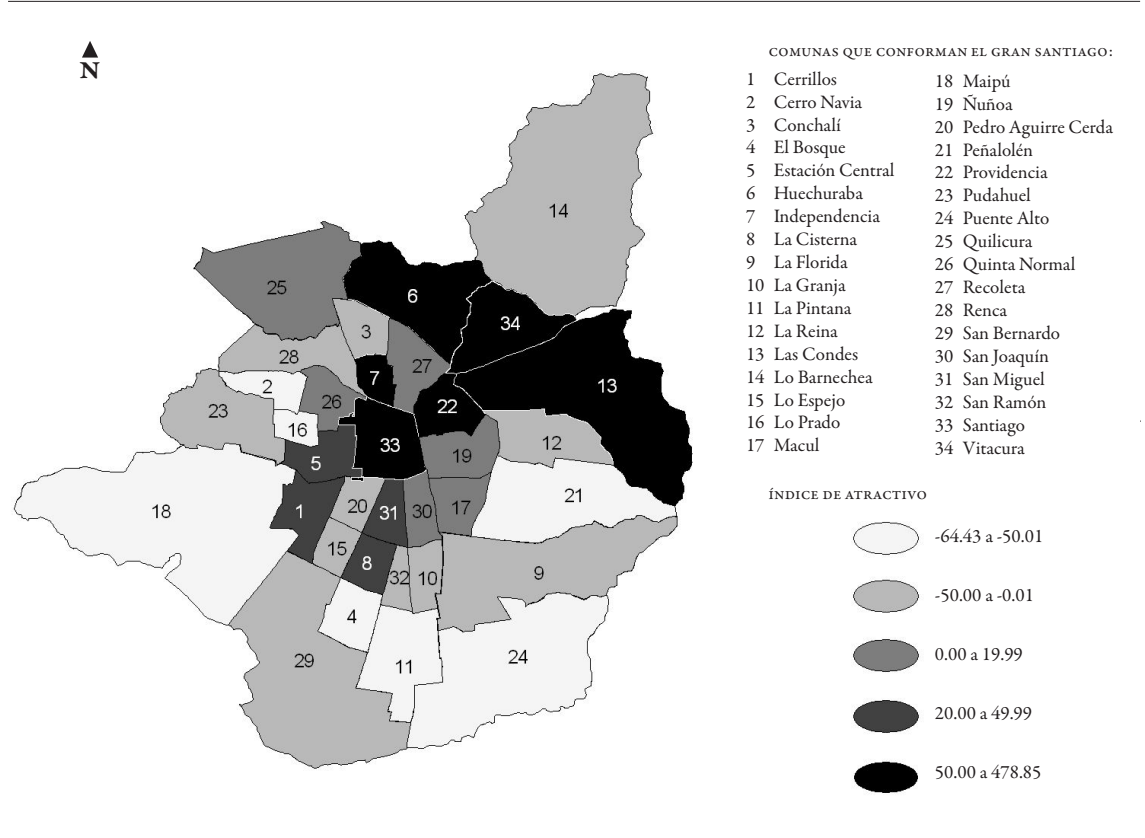

FUENTE ELABORACIÓN PROPIA, VALORES OBTENIDOS MEDIANTE PROCESAMIENTOS ESPECIALES DE LA BASE DE MICRODATOS DE LA CASEN 2009.

nota En algunas comunas (Pudahuel, San Bernardo y Lo Barnechea) Se excluyen distritos rurales. 
CUADRO 4 | AMGS (34 comunas), 2002 y 2009: Evolución del índice de atracción

\begin{tabular}{|c|c|c|c|}
\hline $\begin{array}{l}\text { COMUNA O ZONA DE } \\
\text { RESIDENCIA }\end{array}$ & $\begin{array}{c}\text { ÍNDICE DE } \\
\text { ATRACCIÓN } 2002\end{array}$ & $\begin{array}{c}\text { ÍNDICE DE } \\
\text { ATRACCIÓN } 2009\end{array}$ & $\begin{array}{l}\text { CAMBIO DEL ÍNDICE } \\
\text { DE ATRACCIÓN } \\
2002-2009\end{array}$ \\
\hline Santiago & 3,8 & 5,2 & 1,3 \\
\hline Cerrillos & 1,0 & 1,1 & 0,1 \\
\hline Cerro Navia & 0,1 & 0,1 & 0,0 \\
\hline Conchalí & 0,3 & 0,2 & $-0,1$ \\
\hline El Bosque & 0,2 & 0,1 & $-0,1$ \\
\hline Estación Central & 1,0 & 0,8 & $-0,2$ \\
\hline Huechuraba & 0,9 & 1,0 & 0,1 \\
\hline INDEPENDENCIA & 1,4 & 1,4 & 0,1 \\
\hline La Cisterna & 0,6 & 0,9 & 0,4 \\
\hline LA FLORIDA & 0,3 & 0,2 & 0,0 \\
\hline La Granja & 0,2 & 0,2 & 0,0 \\
\hline La Pintana & 0,1 & 0,1 & 0,0 \\
\hline LA REINA & 0,6 & 0,5 & $-0,1$ \\
\hline Las Condes & 1,3 & 1,2 & $-0,1$ \\
\hline LO BARNECHEA & 0,5 & 0,4 & $-0,1$ \\
\hline Lo EsPejo & 0,3 & 0,3 & 0,0 \\
\hline Lo Prado & 0,1 & 0,1 & 0,0 \\
\hline Macul & 0,7 & 0,8 & 0,0 \\
\hline MAIPÚ & 0,2 & 0,1 & $-0,1$ \\
\hline ÑuÑOA & 0,9 & 0,7 & $-0,2$ \\
\hline Pedro Aguirre Cerda & 0,3 & 0,2 & $-0,1$ \\
\hline Peñalolén & 0,2 & 0,1 & $-0,1$ \\
\hline Providencia & 3,2 & 3,0 & $-0,1$ \\
\hline Pudahuel & 0,4 & 0,4 & 0,0 \\
\hline QUILICURA & 0,9 & 0,6 & $-0,3$ \\
\hline Quinta NormaL & 0,7 & 0,7 & 0,0 \\
\hline Recoleta & 0,7 & 0,8 & 0,0 \\
\hline Renca & 0,5 & 0,4 & 0,0 \\
\hline SAN JOAQUÍN & 0,8 & 0,7 & $-0,1$ \\
\hline SAN Miguel & 1,2 & 1,0 & $-0,3$ \\
\hline SAN RAMÓN & 0,2 & 0,2 & 0,0 \\
\hline VItACURA & 1,2 & 1,5 & 0,3 \\
\hline Puente Alto & 0,1 & 0,1 & 0,0 \\
\hline SAN BERNARDo & 0,4 & 0,3 & $-0,1$ \\
\hline
\end{tabular}

fuente Procesamientos especiales microdatos censo 2002 y Casen 2009. 


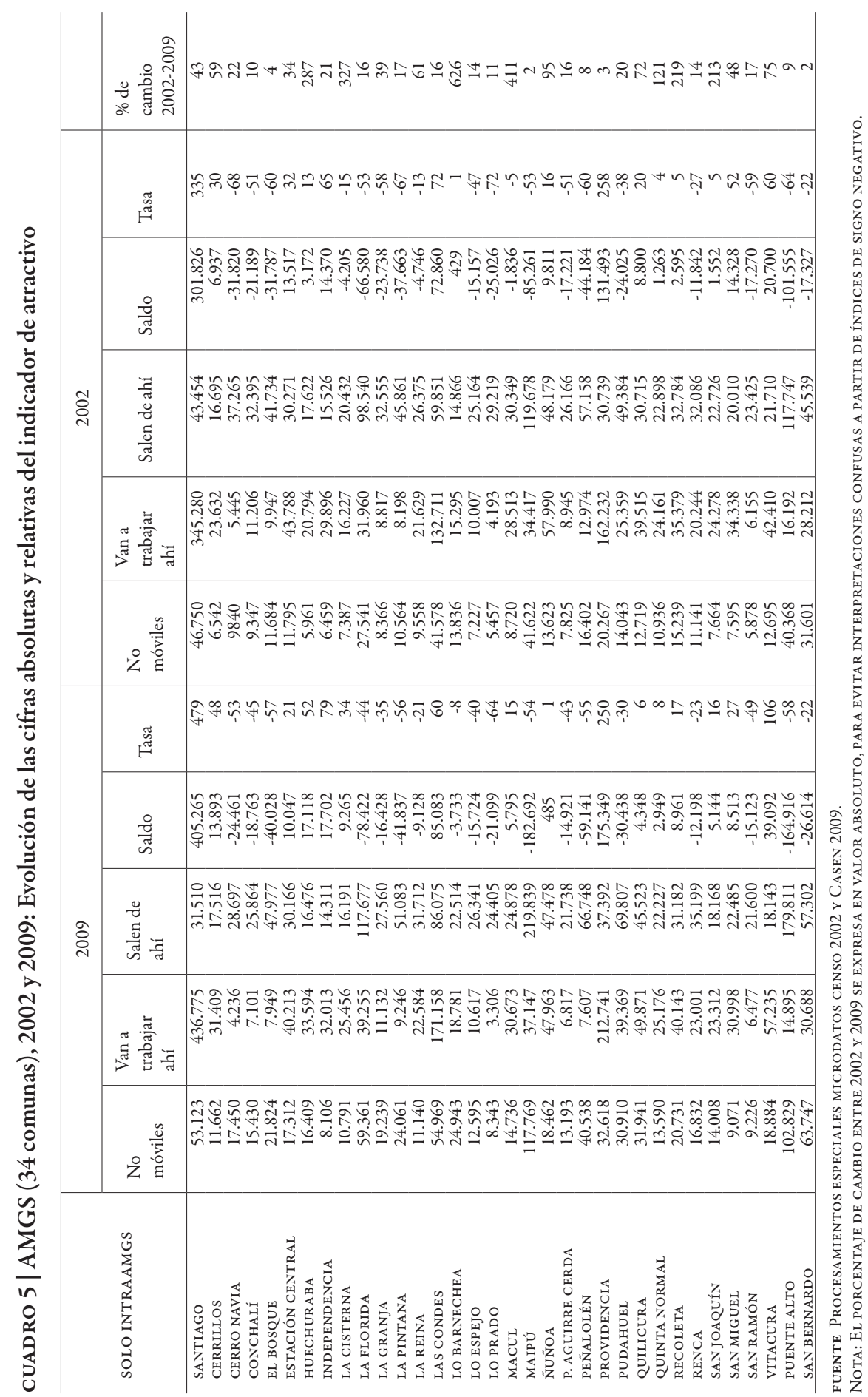




\section{Retención, atracción, atractivo y nivel socioeconómico comunal}

Luego de haber mostrado con diversos indicadores que la centralidad histórica del AMGS mantiene su protagonismo en materia de localización de empleo y atracción de trabajadores, cabe examinar la última hipótesis de la investigación, relativa al vínculo entre movilidad, localización de empleo y nivel socioeconómico de las comunas. Esto se hace de dos maneras. Primero mediante gráficos donde las comunas están ordenadas de acuerdo con su ingreso medio. Y luego mediante una matriz de correlación simple que permite, de paso, evaluar el grado de asociación entre los tres indicadores de movilidad cotidiana comunales usados en este estudio.

Las Figuras 7 a y 7 b muestran que las comunas más pobres y las comunas más ricas están en las antípodas también en materia de atractivo de trabajadores y localización de empleo, ya que mientras las primeras carecen de una base de empleo local robusta (lo que se traduce en una combinación de escasa conmutación para trabajar en ellas y de una significativa conmutación para trabajar fuera de ellas), las segundas concentran una cantidad de empleo que supera con creces su base laboral y, además de dar oportunidades directas de viajes intracomunales a sus residentes, "atrae" trabajadores de todos tipos y de todo el resto de la ciudad. Por cierto, entre estas comunas (todas situadas en el Cono Oriente y que, junto con Santiago, constituyen la centralidad histórica extendida) hay distinciones, existiendo dos que en 2009 tienen un saldo de movilidad negativo (Lo Barnechea y La Reina). Con todo, como se ha reiterado en este trabajo, los ocupados que salen de ambas comunas tienen una muy alta probabilidad de trabajar en la centralidad histórica extendida ( $81,4 \%$ y $72,7 \%$, respectivamente, cifras no mostradas en cuadros), lo que reitera la noción de que la mayoría de las personas de altos ingresos no deben salir de su "hábitat residencial" para trabajar.

Entre estos dos extremos se halla la mayor parte de las comunas del AMGS de niveles socioeconómicos bajos y medios, en cuyos casos el nivel socioeconómico no resulta tan buen predictor de su atractivo, pues otros rasgos adquieren mayor peso, comentados anteriormente al examinar los niveles de atracción de comunas como Independencia, Estación Central, Quinta Normal, San Miguel, Recoleta, San Joaquín y Cerrillos. En general, la evolución de las mismas tiene cierta inercia, porque su relativo abandono en materia habitacional y poblacional — forman parte del pericentro expulsor, según Rodríguez (2008a) - parece no haber erosionado aún su atractivo comercial y productivo. Y si bien el enfoque de las mutaciones metropolitanas posindustriales destaca correctamente las fuerzas que remodelan la periferia y empujan tanto su crecimiento demográfico como la expansión de sus establecimientos y de sus empleos, tiende a olvidar otras fuerzas "conservadoras" que generan continuidad con el pasado (path dependence). Entre ellas está la invariable cercanía al centro comercial histórico, desde luego, y también la resistencia natural a abandonar espacios construidos, pero también están los efectos de la zonificación del uso del suelo (comercial, pequeñas industrias, talleres, etcétera), la estructuración del sistema de transporte colectivo, las redes y el simbolismo creado por la aglomeración de actividades productivas durante largo tiempo, entre otros factores. En contraposición, el enfoque de las mutaciones metropolitanas posindustriales es apoyado por algunas comunas, en particular Huechuraba, la única entre las doce más pobres del AMGS que registra índice de atractivo positivo. 
FIGURA 7A | AMGS, 2002: Índice de atractivo por comuna, ordenadas según nivel de socioeconómico de la comuna

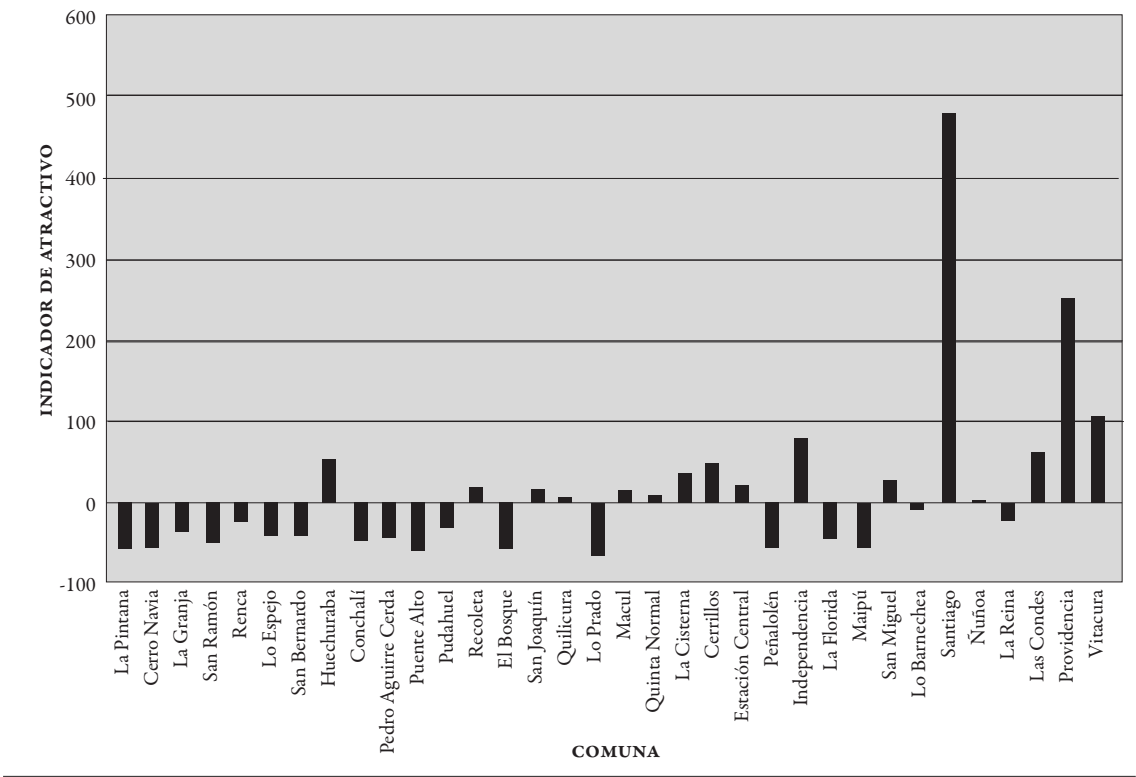

Fuente Procesamientos especiales microdatos Censo 2002.

FIGURA 7B | AMGS, 2009: Índice de atractivo por comuna, ordenadas según nivel de ingreso de la comuna

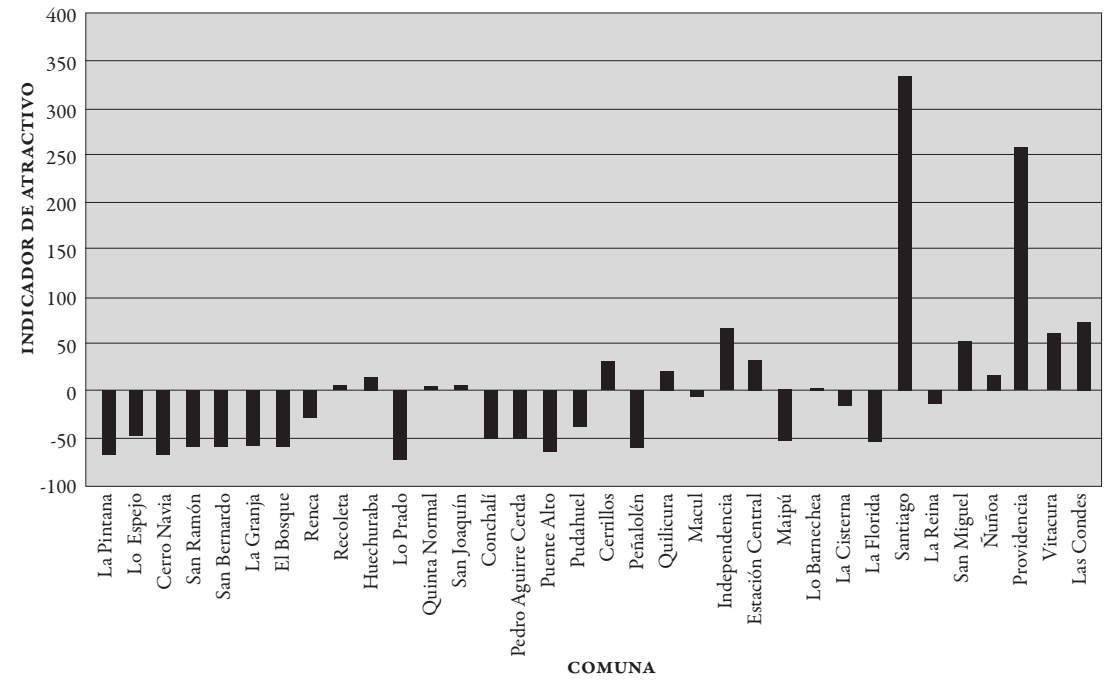

fuente Procesamientos especiales microdatos Casen 2009. 
Finalmente, en el Cuadro 6 se presenta una matriz de intercorrelación simple que resume la asociación estadística entra el nivel socioeconómico y los tres indicadores de la movilidad comunal usados en este trabajo, la cual es, a la vez, una síntesis de la concomitancia entre estos tres indicadores.

Los resultados ratifican las conclusiones extraídas a partir de las Figuras $7 \mathrm{a}$ y $7 \mathrm{~b}$, en particular la existencia de una relación positiva entre el nivel socioeconómico, por una parte, y los tres indicadores de movilidad cotidiana para trabajar a escala comunal usados en este trabajo. Como ya se vio en los acápites previos y en las dos figuras mencionadas, esto se debe al contraste entre los dos extremos socioeconómicos. En efecto, por un lado, el centro comercial extendido está compuesto por las comunas ricas del Cono Oriente que, dada la concentración del empleo en ese centro, sobresalen por altos índices de atracción y de retención (por ello registran índices descollantes de atractivo). Por otra parte, las comunas pobres de la periferia y del pericentro aún tienen niveles limitados de retención y sus índices de atracción son muy bajos (en parte por su localización excéntrica, y en parte porque el efecto de creación de empleo de los subcentros emergentes es aún muy acotado). Dado que en estas comunas se encuentra una fracción significativa de los ocupados del AMGS, muchos de ellos — hombres y mujeres - no tienen más alternativa para estar empleados que recorrer grandes distancias hasta el centro comercial ampliado o las subcentralidades históricas del pericentro.

Ahora bien, los resultados del Cuadro 6 muestran un debilitamiento del vínculo, que incluso deviene no significativo estadísticamente en el caso de la relación entre nivel socioeconómico e índice de retención. Esto obedece a que el aumento generalizado de la retención fue menos intenso en las comunas más ricas, entre otros factores porque estas últimas tenían niveles de retención ya muy elevados en 2002. Cualquiera sea el caso, estos resultados sugieren, en general, algunos cambios, en particular en materia de retención, que podrían explicarse por la difusión objetiva de los artefactos de la globalización a través del AMGS. Pero se requiere mucha investigación empírica adicional para verificar este vínculo.

Un punto destacable es la diversidad del empleo en el centro comercial ampliado, que se intuye de los resultados expuestos en este trabajo. En efecto, la convergencia allí de ocupados provenientes de todas las comunas del AMGS es indicativa de tal diversidad, considerando las marcadas diferencias sociales que existen entre las comunas del "barrio alto" y las del resto del AMGS. Por cierto, se trata de un tema que requiere de mayor indagación y que debe ser hecho con una aproximación distinta a la usada en este trabajo (individual en vez de comunal). Pero su eventual comprobación sería clave para entender por qué esta concentración del empleo en el "barrio alto" no genera un desajuste (mismatch) entre residencia y ocupación para sus habitantes, ya que al estar el grueso de los empleos de comando, control, coordinación y supervisión (bien remunerados) aún localizados en el centro comercial ampliado, las personas de altos ingresos no necesitan, en general, salir de allí para trabajar. En suma, se necesita seguir investigando y usar no solo el enfoque agregado (análisis comunal), sino también indagar en la intensidad y los destinos de la movilidad cotidiana para trabajar de las personas o grupos de personas. 
CUADRO 6 | AMGS: Matriz de intercorrelación simple entre nivel socioeconómico de la comuna e indicadores seleccionados de movilidad cotidiana para trabajar

\begin{tabular}{l|c|c|c|c|c|c|c|c}
\hline & \multicolumn{2}{|c|}{ INDICADOR DE INGRESO } & \multicolumn{2}{|c|}{ RETENCIÓN } & \multicolumn{2}{c|}{ ATRACCIÓN } & \multicolumn{2}{c}{ ATRACTIVO } \\
\cline { 2 - 9 } & 2002 & 2009 & 2002 & 2009 & 2002 & 2009 & 2002 & 2009 \\
\hline INGRESO & 1 & 1 & & & & & & \\
RETENCIÓN & 0,507031 & 0,210534 & 1 & 1 & & & & \\
ATRACCIÓN & 0,607536 & 0,518621 & 0,689395 & 0,609959 & 1 & 1 & & \\
ATRACTIVO & 0,616947 & 0,515478 & 0,739262 & 0,65569 & 0,996947 & 0,997855 & 1 & 1 \\
\hline
\end{tabular}

FUENTE PROCESAMIENTOS ESPECIALES MICRODATOS CASEN 2009.

NOTA TODOS LOS COEFICIENTES ESTADÍSTICAMENTE SIGNIFICATIVOS PARA UNA MUESTRA DE 34 CASOS Y CON UN NIVEL DE SIGNIFICACIÓN DE 95\%, SALVO EL 0,210534.

\section{Conclusiones y desafíos}

De Mattos (2010) ha identificado, de manera genérica, múltiples implicancias para las formas de políticas y de la cotidianidad derivadas de las mutaciones metropolitanas posindustriales, entre ellas el tránsito de ciudades monocéntricas a pluricéntricas. Galetovic y Jordan (2006) precisan estas implicancias para el AMGS y las exponen de una manera práctica en ámbitos como el transporte, el ajuste entre empleo y residencia, etcétera. Verificar si estas consecuencias efectivamente se producen, se impone como desafío para los cientistas sociales.

Pero antes de ello, cabe mirar con más atención la realidad de las ciudades latinoamericanas y examinarlas considerando sus especificidades históricas - entre las cuales resaltan la desigualdad y su heterogeneidad estructural y espacial- y las implicaciones que ello tiene para las mutaciones metropolitanas. En el caso del AMGS, por ejemplo, una especificidad histórica sobresaliente es el contraste entre la segregación residencial — cuyo atributo más notable es la concentración del grupo de mayor nivel socioeconómico en el denominado barrio alto-y la co-presencia diaria de casi todos los segmentos socioeconómicos en dicha zona, producto de la diversidad de la gran demanda de empleo que se localiza allí. Las hipótesis de difusión, desconcentración y multiplicación de subcentralidades en las metrópolis tienen sólidos argumentos conceptuales, pero no son verdades a priori. Más aún, considerando la existencia de argumentos que matizan la inexorabilidad de su avance y que cuestionan la existencia de un formato único para el proceso, hay un trabajo de comprobación empírica que aún tiene pendiente esta hipótesis.

De hecho un estudio reciente que compara algunos análisis de metrópolis concretas, donde se ha investigado si hay una mutación hacia una ciudad policéntrica, concluye que "algunos autores han acogido la tesis con entusiasmo, otros con mayor cautela y en un buen número de casos ha dado lugar a la revisión detallada de sus componentes sin la posibilidad de suscribirla de forma completa y contundente" (Cuervo, 2010, p. 18). 
En esta última línea de cuestionamiento se anota este trabajo, cuyos resultados presentados revelan la potencial coexistencia de un tímido proceso de emergencia de subcentralidades, con una persistencia - bajo una nueva escala geográfica, por cierto- de la centralidad comercial histórica. Adicionalmente, muestran una inesperada resistencia de las subcentralidades antiguas, las cuales aún captan una fracción importante de los viajes de trabajo, lo que matiza todavía más la relevancia actual de las subcentralidades emergentes como espacio de atracción de trabajadores del resto del AMGS. ${ }^{13}$

\section{Referencias bibliográficas}

Angel, S., Parent, J., Civco, D. I. \& Blei, A. (2011). Making room for a planet of cities. Washington, DC: Lincoln Institute, www.lincolninst.edu/pubs/1880_Making-Room-for-a-Planet-ofCities-urban-expansion.

Aroca, P. (2007). Impacto sobre el crecimiento regional de la migración y conmutación interregional en Chile. Taller Nacional sobre "Migración interna y desarrollo en Chile: diagnóstico, perspectivas y politicas”. Comisión Económica para América Latina y el Caribe (Cepal), 10 de abril 2007, Santiago, Chile, http://www.cepal.org/celade/noticias/paginas/5/28295/ PAroca.pdf.

Cuervo, L. M. (2010), América Latina: metrópolis en mutación [mimeo].

De Mattos, C. (2001). Metropolización y suburbanización. EURE, 27(80), 5-8. doi: 10.4067/S025071612001008000001 .

De Mattos, C. (2010). Globalización y metamorfosis metropolitana en América Latina. De la ciudad a lo urbano generalizado. Revista de Geografía Norte Grande, n. ${ }^{\circ} 47,81-104$. doi: 10.4067/ S0718-34022010000300005.

De Mattos, C., \& Hidalgo, R. (Eds.) (2007). Movilidad espacial y reconfiguración metropolitana. Santiago de Chile: Instituto de Estudios Urbanos, Pontificia Universidad Católica de Chile, Colección EURE-Libros/Instituto de Geografía, Pontificia Universidad Católica de Chile, Serie GEOlibros, n. ${ }^{\circ} 8$.

Delaunay, D. (2010). Mobilités, ségrégations résidentielles et bonus démographique dans la zone métropolitaine de Santiago du Chili. Revue Tiers monde, n. ${ }^{\circ}$ 201, 65-85.

Dureau, F. y V. Gouëset (2010). Formes de peuplement et inégalités de déplacements. Revue Tiers monde, n. $201,131-156$.

Escolano, S. \& Ortiz, J. (2005). La formación de un modelo policéntrico de la actividad comercial en el Gran Santiago (Chile). Revista de Geografia Norte Grande, n. ${ }^{\circ} 34,53-64$.

Galetovic, A. \& Jordán, P. (2006). Santiago: ¿Dónde estamos? ¿Hacia donde vamos? Estudios Públicos, n. ${ }^{\circ} 101,87-145$.

13

Ciertamente, se trata de un asunto que amerita investigación en muchas otras ciudades de América Latina, donde, como plantea Cuervo en una ponencia reciente, "presenciamos emergencia de nuevas morfologías y tamaños de ciudad, en algunos casos obedeciendo al patrón de la ciudad difusa, en otros combinándolo con la existencia de un centro indiscutible, y en otros, simplemente remodelando la escala y la forma del monocentrismo" (Cuervo, 2010, mimeo, p. 28). 
Graham, S. y S. Marvin (2001). Splitering urbanism: Networked infrastructures, technological mobilities and the urban condition. Londres: Routledge.

Hall, P. (1996). Ciudades del mañana. Historia del urbanismo en el siglo XX. Barcelona: Ediciones del Serbal.

Ingram, G. (1998). Patterns of metropolitan development: What have we learned? Urban Studies, 35(7), 1019-1035.

Janoschka, M. (2002). El nuevo modelo de la ciudad latinoamericana: fragmentación y privatización. EURE, 28(85), 11-20. doi: 10.4067/S0250-71612002008500002.

Jiménez, M. (2009). Potencialidades de la medición de la movilidad cotidiana a través de los censos. Notas de Población (Santiago), n. ${ }^{\circ} 88,163-186$

Orellana, A. (2009). La gobernabilidad metropolitana de Santiago: la dispar relación de poder de los municipios. EURE, 35(104), 101-120. doi: 10.4067/S0250-71612009000100005.

Roberts, B. \& Wilson, R. (Eds.). (2009). Urban segregation and governance in the Americas. Nueva York: Palgrave-Macmillan.

Rodríguez, J. (2007). Paradojas y contrapuntos de dinámica demográfica metropolitana: algunas respuestas basada en la explotación intensiva de microdatos censales. En C. de Mattos \& R. Hidalgo (Eds.), Santiago de Chile: Movilidad espacial y reconfiguración metropolitana (pp. 19-52). Santiago: Pontificia Universidad Católica de Chile.

Rodríguez, J. (2008a). Movilidad cotidiana, desigualdad social y segregación residencial en cuatro metrópolis de América Latina. EURE, 34(103), 49-71.

Rodríguez, J. (2008b). Dinámica sociodemográfica metropolitana y segregación residencial: ¿qué aporta la Casen 2006? Revista de Geografía Norte Grande, n. ${ }^{\circ} 41,81-102$.

Rodríguez, J. (2010). Dinámica demográfica y asuntos urbanos y metropolitanos en América Latina: ¿qué aporta el procesamiento de microdatos censales? En F. Sabatini, R. Salcedo, G. Wormald \& G. Cáceres (Eds.), Tendencias de la segregación en las principales ciudades chilenas. Análisis censal 1982-2002 (pp. 93-114). Santiago: Universidad Católica de Chile/Instituto Nacional de Estadísticas de Chile (INE).

Sabatini, F. \& Cáceres, G. (2004). Los barrios cerrados y la ruptura del patrón tradicional de segregación en las ciudades latinoamericanas: El caso de Santiago de Chile. En G. Cáceres \& F. Sabatini (Eds.), Barrios cerrados en Santiago de Chile: entre la exclusión y la integración residencial (pp. 9-43). Santiago: Lincoln Institute/Pontificia Universidad Católica de Chile.

Tokman, A. (2006). El Minvu, la política habitacional y la expansión excesiva de Santiago. En A. Galetovic \& P. Jordán (Eds.), Santiago: ¿Dónde estamos? ¿Hacia dónde vamos? (pp. 489-520). Santiago: Estudios Públicos.

Wheaton, W. (2002). Dispersed employment, commuting and mixed land-use in modern cities. Cambridge, MA: Massachusetts Institute of Technology. [En línea] http://web.mit.edu/cre/ research/papers/wp84wheaton.pdf. 
